\title{
ADIYAMAN AĞZI SÖZ VARLIĞINA İLAVELER: ATASÖZLERİ VE
} DEYIMLER

\author{
Muhammet Fatih ALKAYIŞ ${ }^{1}$
}

Davşan yèrímesse dağ yėrír.

(Adıyaman Ağzından)

\begin{abstract}
Özet
Adıyaman ağzında çok sayıda atasözü ve deyim yaşamaktadır. Adıyaman ağzının zenginlik kaynağı olan bu atasözü ve deyimler üzerine yapılan çalışmaların sayısı gün geçtikçe artmaktadır. Söz konusu çalışmalar hem Adıyaman ağzı hem de Türk dili için büyük öneme sahiptir. Bu makalede, Adıyaman ağzından derlenen 7'si atasözü, 15'i deyim olmak üzere toplam 22 adet söz varlığı, çeviri yazı işaretleriyle birlikte verilmiş ve değerlendirilmiş̧ir. $\mathrm{Bu}$ atasözü ve deyimler, 2012 ve 2019 yıllarında şahsım tarafindan yayımlanan "Adıyaman Ağzında Atasözleri ve Deyimler" ve “Adıyaman A ğzında Atasözleri ve Deyimler-2" başlıklı kitaplardan sonra derlendiği için burada bir makale içerisinde sunulmuştur. Sözlü dilde yaşayan bu malzemeler kayıt altına alınarak hem unutulmaktan kurtarılmış hem de insanların istifadesine sunulmuştur.
\end{abstract}

Anahtar kelimeler: Adıyaman ağzı, atasözleri, deyimler.

\section{ADDITIONS TO ADIYAMAN DIALECT: PROVERBS AND IDIOMS}

\begin{abstract}
There are many proverbs and idioms in the dialect of Adiyaman. The number of studies on these proverbs and idioms, which are the source of wealth of the dialect of Adiyaman, is increasing day by day. These studies are of great importance both for the Adiyaman dialect and for the Turkish language. In this article, a total of 22 vocabulary, 7 proverbs and 15 idioms collected from Adiyaman dialect, are given and evaluated with translation writing signs. These proverbs and idioms are presented here in an article because they were compiled after the books titled "Adıyaman Ağzında Atasözleri ve Deyimler" and "Adıyaman Ağzında Atasözleri ve Deyimler2" published by myself in 2012 and 2019. These materials, which live in verbal language, were recorded and saved from oblivion and presented to the benefit of people.
\end{abstract}

Key words: Adiyaman dialect, proverbs, idioms.

\section{GİRIS}

Adıyaman yöresinde çok sayıda atasözü ve deyim yaşamaktadır. Bunlar, Adıyaman ağzının birer zenginliğidir. Yöre insanının kendi aralarındaki konuşmalarına

\footnotetext{
${ }^{1}$ Doç. Dr., İnönü Üniversitesi Fen Edebiyat Fakültesi Türk Dili ve Edebiyatı Bölümü, fatih.alkayis@inonu.edu.tr
} 
kulak verildiğinde onların atasözü ve deyimlere çok sık yer verdikleri görülür. Karı ile koca, kaynana ile gelin, esnaf ile esnaf veya esnaf ile müşteri arasında gerçekleşen konuşmaların belli bir bölümünü atasözleri ve deyimler oluşturmaktadır.

"Türkiye Türkçesi ağızları, gramer özellikleri bakımından sadece dilbilgisi (ses bilgisi, şekil bilgisi, cümle bilgisi ve anlam bilgisi) için değil; sosyoloji, tarih, sanat tarihi, etimoloji gibi birçok bilim dalı için başvuru kaynağıdır" (Yavuz ve Bulduk, 2013: 406). "Adıyaman, yurdumuzun Güneydoğu Anadolu Bölgesi sınırları içerisinde yer alan, geleneksel kültürün yoğun olarak yaşandığı bir ildir” (Nakiboğlu, 2001: 27). "Gelenek ve görenekler bir bölge için çok önemlidir... Yöre ağzının değişmez unsurları olarak yıllardan beri varlığını sürdüren kalıp sözler de gelenek ve göreneklerin ürünü olarak ortaya çıkarlar" (Yavuz, 2013: 58).

"Çok eski bir yerleşim yeri olan bu il, günümüze kadar çeşitli kültürlere ev sahipliği yapmıştır” (Yağınlı, 2006: 175). Adıyaman ağzı, Batı Grubu Ağızlarının VII. alt grubunda yer almaktadır (Karahan, 1996: 1, 2). Birkaç yıl öncesine kadar Adıyaman ilinin kültürü ve ağzı üzerine yapılan çalışmalar oldukça sınırlıydı; ancak, son yıllarda ortaya konan çalışmalar (makale ve kitaplar) belli bir seviyeye ulaşmıştır.

\section{Atasözleri ve Deyimler Üzerine Yapılan Bazı Tanımlar}

Atasözleri ve deyimlerin tanımı, izlenen üslup ve seçilen sözcükler bakımından, yazardan yazara veya kitaptan kitaba farklılıklar göstermektedir. Ayrıca, bunlar üzerine yapılan değerlendirmelerin ağılık noktaları da kaynaklara göre değişmektedir. Atasözleri ve deyimler üzerine yapılan tanımlardan ve açıklamalardan bazılarını şöyle srralayabiliriz:

\section{Atasözleri}

"Uzun deneme ve gözlemlere dayanılarak söylenmiş ve halka mal olmuş, öğüt verici nitelikte söz, darbımesel” (Türkçe Sözlük, 2005: 140).

"Atalarımızın, uzun denemelere dayanan yargılarını genel kural, bilgece düşünce ya da ögüt olarak düsturlaştıran ve kalıplaşmış biçimleri bulunan kamuca benimsenmiş özlü sözler" (Aksoy, 1993: 37).

"Uzun deneme ve gözlemlere dayanan düşüncelerden doğan, kesin hükümler içeren, bilgece bir tavırla ögüt verir ve yol gösterir nitelikte olan, yüzyıllar boyu sözlü geleneğin içinde beslenerek halk tarafından benimsenmiş bulunan ve de halkın ortak değer yargılarını taşıyan kalıplaşmış özlü sözlerdir” (Parlatır, 2007 A: 2).

\section{Deyimler}


"Genellikle gerçek anlamından az çok ayrı, ilgi çekici bir anlam taşıyan kalıplaşmış söz öbeği, tabir” (Türkçe Sözlük, 2005: 517).

"Bir kavramı, bir durumu, ya çekici bir anlatımla ya da özel bir yap1 içinde belirten ve çoğunun gerçek anlamlarından ayrı bir anlamı bulunan kalıplaşmış sözcük topluluğu ya da tümce" (Aksoy, 1993: 52).

"En az iki söz varlığından oluşan ve gerçek anlamları dışında mecazî anlam ile pekiştirilmiş bulunan kalıplaşmış söz öbeği ya da deyiş" (Parlatır, 2007 B: 1).

"Genellikle birden çok sözcükten kurulan deyimler, seyrek olarak da tek bir sözcügün yan anlamda kullanılmasıyla oluşabilir”" (Aksan, 1996: 91).

\section{Değerlendirme}

"Ağızlar, Türk dilinin bölgesel ve yöresel farklılıklar gösteren küçük kollarıdır" (Bulut, 2018: 173). "Türkiye'de ağız çalışmalarının tarihi 1932 yılına, o zamanki adı Türk Dili Tetkik Cemiyeti olan Türk Dil Kurumu tarafından yapılan çalışmalara dayanmaktadır" (Telli ve Bulduk, 2018: VII). Her ağız çalışması, geçmişten günümüze sunulan ve aynı zamanda geleceğe kalacak olan kıymetli birer belgedir. Ağız çalışmalarındaki bilgiler, halkı; konuşma biçimi, yaşam felsefesi, mutfak ve eğlence kültürü, gelenek ve görenekleriyle birlikte bir bütün olarak yansıtır.

Adıyaman ağzı atasözleri ve deyimleri üzerine uzun soluklu derleme ve değerlendirme çalışmaları sonucunda yayımlamış olduğum "Adıyaman Ağzında Atasözleri ve Deyimler" (2012) ve "Adıyaman Ağzında Atasözleri ve Deyimler-2" (2019) adlı eserlerde Adıyaman ilinde kullanılan çok sayıda atasözü ve deyim ele alınmıştır. Söz konusu kitapların yayımlanmasından sonra, karşıma yeni yeni atasözleri ve deyimler çıktı. Onları da bu makale içerisinde değerlendirmek istedim.

\section{Adıyaman Ăgzında Atasözleri}

\section{Alnının teríní siyírmemíş ki yüregi aciya.}

Kendi emeğiyle, kendi alın teriyle çalışıp kazanmamış ki harcama yaptığında yüreği acısın. Rahatlıkla harcayabildiğine göre ya babasından kalmıştır ya da bedavadan gelmiştir.

İşlenen kavramlar: Savurganlık, acımasızlık.

\section{EşşeG çamıra düşerse seĥebínden çoh çarpınan olmaz.}


Zor durumda olan bir evlat için en çok koşturan, en çok telaşlanan onun anne-babası veya kardeşidir. Başka hiç kimse onlar kadar üzülmez, çırpınmaz.

İşlenen kavramlar: Yakınlık, çırpınma.

\section{Gendí gözzel olacağına baћtı gözzel olsın.}

Bir anne için kızının baht güzelliği, yüz güzelliğinden daha önemlidir.

İşlenen kavramlar: Yeğleme.

\section{Herkeşín surfasında yanı̆ eGmeG vardır.}

Geçmişte her insan hata yapmıştır. Kimsenin mazisi kusursuz değildir. Bir insan başka bir insanı eleştirmeden önce kendisine baksın. O zaman görecektir ki kendisinin de eskiden bazı yanlışları olmuştur.

İşlenen kavramlar: Geçmişte yapılan hatalar.

\section{Oğlımın oğlı boḳķımın oğlı, ķızımın oğlı gözímín nurı.}

Kaynana kendi gelinini sevmediği zaman o gelinin doğurduğu çocuğu da sevmez; ama kendi kızının çocuğunu sever, çünkü o torunun annesini kendisi doğurmuştur.

İşlenen kavramlar: Nefret ve sevgi.

\section{Oğlan olsın da ot kökí olsın.}

Doğacak çocuk oğlan çocuğu olsun da nasıl olursa olsun. Yeter ki oğlan olsun.

İşlenen kavramlar: Tek bir sonuca bağlanma.

\section{Oğlan çocığı, ķapı kilídí.}

K1z çocuğu gelin olup başka bir eve gider. Oğlan çocuğu ise o evin esas sahibidir, hiçbir yere gitmez ve anasına bakar.

İşlenen kavramlar: Kıymet, önem.

\section{Adıyaman Ağzında Deyimler}

\section{Allah ķavunı tiyegínde böyítsín.}


Yeni doğan çocuk için "Allah analı babalı büyütsün” anlamında kullanılan bir deyim. "Tiyek" sözcüğü, topraktan çıkan ana dal demektir. "Kavun" ise bu deyimde "evlat" anlamindadir.

İşlenen kavramlar: Temenni, merhamet.

\section{Allah vère (gelsin, yapsın / gel, yap...).}

Fiillerin başında kullanılan bu deyim (Allah vère); bir başkasına gözdağı vermek veya onu korkutmak amacıyla kullanılmaktadır. Erkekse gelsin, erkekse yapsın / erkeksen gel, erkeksen yap vb. anlamlara gelmektedir.

İşlenen kavramlar: Meydan okuma, gözdağı.

\section{Çarşı ağası.}

Bu deyim "zabıta" anlamında kullanılmaktadır. Zabıtalar çarşıyı, esnafları denetler; bu yüzden çarşının ağası sayılırlar.

İşlenen kavramlar: Yetki, hâkimiyet.

\section{Davşan boḳı gibí ne ķohmah ne bılaşmah.}

Bir şeyin bir kişiye ne fayda ne de zarar sağlaması, ne olduğunun tam olarak anlaşılmaması, tanımlanamayan özellikte olması.

İşlenen kavramlar: Belirsizlik, anlaşılmazlık.

\section{Dilí kira istemek.}

Hiç konuşmayan, herhangi bir konuda yorum yapmayan, olaylar karşısında sürekli sessiz kalan kimseler için kullanılan bir deyim.

İşlenen kavramlar: Suskunluk.

\section{Dünyada yaş bırahmamah.}

Çok yaşı kimseler için kullanılan bir deyim.

İşlenen kavramlar: İleri yaşta olma.

\section{Ĥaḳ dẻrse yimek húụ́ dèrse su.}


Bir kimseye sürekli ikramda bulunmak, onun önünden yiyecek ve içeceği eksik etmemek.

İşlenen kavramlar: İkramda kusur etmeme.

\section{Harar gibí olmah. ${ }^{2}$}

Giydiği elbise kendisine bol gelmek, çok geniş olmak.

İşlenen kavramlar: Bol gelme, abartılı görünüm.

\section{Hepsínín yükíní k̦aldırmah.}

Bir ailenin önde gelen kişisi, bazı durumlarda bütün ailesini temsil eder, tek başına diğer bireylerin yerini doldurur. Örneğin, bir taziye ziyaretine gelen kimse, kendi ailesinin tamamını orada temsil eder.

İşlenen kavramlar: Temsil, kabiliyet.

\section{Küpe sıçan düşmek.}

Bir gelinin evlendikten bir süre sonra hamile kalması, çocuk doğuracak olması. Çevre, yeni evlenen gelinin hamile olup olmadığını öğrenmek için "Küpe sıçan düştü mü?" şeklinde sorar.

İşlenen kavramlar: Merak, soruşturma.

\section{Maşşalla dẻdígí üş gün yaşamamah. ${ }^{3}$}

Yolunda giden bir işe veya sağlıkı bir insana nazarı değen kişiler için kullanılan bir deyim.

İşlenen kavramlar: Nazar.

\section{Olanı tökmek.}

Elde ne varsa ortaya koymak, ikram etmek.

İşlenen kavramlar: Doğallık.

\footnotetext{
${ }^{2}$ Harar kelimesi Adıyaman ağzında "büyük çuval” anlamına gelmektedir. Sözlük anlamı ise şöyledir: "harār (< Arapça gırār) Keçi kılından örme büyük çuval" (Parlatır, 2009: 581).

${ }^{3}$ Maşallah > Maşşalla; üç > üş (-ç > -ş). 


\section{Taralillo gibí gezmek. ${ }^{4}$}

Akılsızca ve amaçsızca gezmek, işsiz güçsüz dolaşmak.

İşlenen kavramlar: Benzetme.

\section{Fıllanė gibí ortiya düşmek. ${ }^{5}$}

Oradan oraya dolaşmak. Gezip durmak.

İşlenen kavramlar: Benzetme.

\section{Zambirlanmah.}

Bir davranış veya bir söze çok sinirlenmek, yerinde duramayacak kadar öfkelenmek; aşırı kızgınlık durumu.

İşlenen kavramlar: Kızgınlık.

\section{Sonuç}

"Ağızlar filoloji çalışmaları için önemli bir kaynak durumundadır" (Telli ve Bulduk, 2019: 99). "A ğız bilimi çalışmaları stratejik dil çalışmaları olarak değerlendirilmektedir. Dolayısıyla bir dilbilimi terimi olarak ağızlar ile ilgili yapılacak çalışmalar toplumların var olduklarının kanıtları, geleceğe dair kayıtlardır” (Yavuz, 2013: 19).

“Adıyaman, Güneydoğu Anadolu Bölgesi’nin batısında Akdeniz Bölgesi’yle birleşen noktada yer alır" (adiyaman.ktb.gov.tr). Adıyaman ağzı, Türkiye Türkçesi ağızları içerisinde atasözü ve deyim kullanımı bakımından önemli bir yere sahiptir. Yöre insanı, adeta zihinlerine kazınmış olan bu söz varlıklarını, herhangi bir çağrışım veya konuşma esnasında kullanmakta ya da yaşanan bir olaya örnek göstermektedir.

Bu makalede, Adıyaman ağzından derlenen 7'si atasözü, 15'i deyim olmak üzere toplam 22 adet söz varlığı, çeviri yazı işaretleriyle birlikte verilmiş ve değerlendirilmiştir. Buradaki atasözlerinde genel olarak şu kavramlar işlenmiştir: Savurganlık, acımasızlık; yakınlık, çırpınma; yeğleme; geçmişte yapılan hatalar; nefret ve sevgi; tek bir sonuca bağlanma; kıymet, önem. Deyimlerde ise şu kavramlar

\footnotetext{
4 “Taralillo" kelimesi Adıyaman ağzında "aklı bir karış havada, salak” anlamına gelmektedir. (Bu bilgi Hamit ÖZER'den alınmıştır.)

5 “Fıllanè” kelimesi, Adıyaman ağzında, izarını (çarşafını) omzuna atıp gezen, eviyle ilgilenmeyen vurdumduymaz kadınlar için kullanılmaktadır. (Bu bilgi Hamit ÖZER'den alınmıştır.)
} 
işlenmiştir: Temenni, merhamet; meydan okuma, gözdağı; yetki, hâkimiyet; belirsizlik, anlaşmazlık; suskunluk; ileri yaşta olma; ikramda kusur etmeme; bol gelme, abartılı görünüm; temsil, kabiliyet; merak, soruşturma; nazar; doğallık; benzetme; kızgınlık.

Sözlü dilde varlığını sürdüren bu atasözleri ve deyimler yazıya aktarılarak hem unutulmaktan kurtarılmış hem de sonraki kuşaklara miras bırakılmak üzere korunmaya alınmış bulunmaktadır. Bu tür çalışmalar, Türk dilinin anlam dünyası ve söz varlığııın zenginleştirilmesi konusunda ortaya konacak önemli katkılardandır.

\section{Çeviri Yazı İşaretleri:}

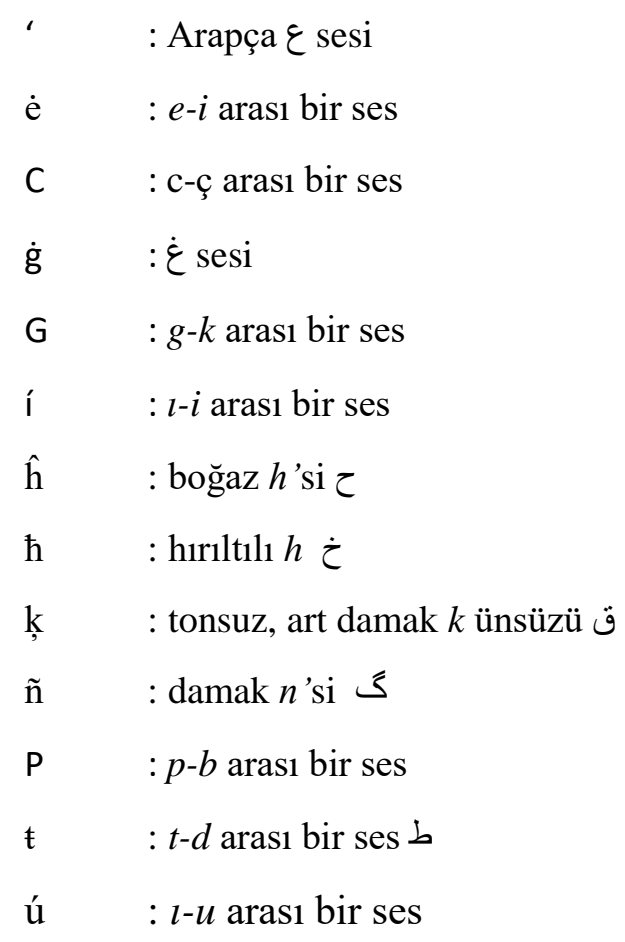

\section{KAYNAKÇA}

Aksan D. (1996). Türkçenin Sözvarlı̆̆l, Engin Yayınevi, Ankara.

Aksoy Ö. A. (1993). Atasözleri ve Deyimler Sözlüğü 1, İnkılâp Yayınları, İstanbul.

Alkayış M. F. (2012). Adıyaman Ağzında Atasözleri ve Deyimler, Ankara: Öncü Yayınları.

Alkayış M. F. (2019). Adıyaman Ağzında Atasözleri ve Deyimler - 2, İstanbul: Hiperyayın.

Bulut S. (2018). “Gümüşhane İli ve Yöresi Ağızlarından Derleme Sözlüğ̈̈’ne Katkılar”, Karadeniz Araştırmaları, XV/57-Bahar 2018, s.171-190 (www.karam.org.tr, erişim tarihi: 27.12.2019).

Karahan L. (1996). Anadolu Ă̆ızlarının Sinıflandırılması, Ankara: TDK Yayınları. 
Nakiboğlu S. H. (2001). Adıyaman ve Yöresi Ağızları, Niğde: Niğde Üniversitesi Yayınları.

Parlatır İ. (2007 A). Atasözleri, Ankara: Yarg1 Yayınevi.

Parlatır İ. (2007 B). Deyimler, Ankara: Yarg1 Yayınevi.

Parlatır İ. (2009). Osmanlı Türkçesi Sözlüğü, Ankara: Yargı Yayınevi.

Telli B. \& Bulduk T. B. (2018). Adıyaman İli ve Yöresi A ̈̆ızları Söz Varlı̆̆ı, Aralık-Ankara: Gazi Kitabevi.

Telli B. \& Bulduk T. B. (2019). “Adıyaman İli ve Yöresi Ağızlarından Derleme Sözlüğü’ne Katkılar: Fiil”, HIKMET-Akademik Edebiyat Dergisi (Journal of Academic Literature), Y11 5, Say1 10, Bahar 2019, ss.98-115.

Türkçe Sözlük (2005). Ankara: Türk Dil Kurumu Yayınları.

Yağınlı A. Â. (2006). Adıyaman Ağzı ve Kültürü, Adıyaman: Adıyaman Belediyesi Yayınları.

Yavuz S. (2013). Adıyaman İli ve Yöresi Ağızları, 1. Baskı, Ekim-Ankara: Turkish Studies Yayınları.

Yavuz S. \& Bulduk T. B. (2013). “Aboş” Kelimesinin Kökeni ve Anlamı, Tarih Okulu Dergisi (TOD), Sayı XV, ss. 405-412, (https://docplayer.biz.tr, erişim tarihi: 27.12.2019).

\section{İnternet Kaynakları:}

adiyaman.ktb.gov.tr (erişim tarihi: 13.11.2019)

Google.com (erişim tarihi: 13.11.2019; 27.12.2019)

translate.google.com (erişim tarihi: 13.11.2019)

\section{Kaynak Kişiler $^{6}$}

ALKAYIŞ Gazi, Sanat Tarihçisi, Adıyaman.

ALKAYIŞ Sıddık, Berber, Adıyaman.

ALKAYIŞ Saadet, Ev Hanımı, Adıyaman.

HANBAY Güllü, Vefat, Adıyaman.

HANBAY Mahmut, Vefat, Adıyaman.

KALAYCI Eşref, Emekli, Adıyaman.

ÖZER Hamit, Terzi, Adıyaman.

SÜRÜCÜ Mustafa, Öğretim Üyesi, Adıyaman.

TUNCER Emik, Vefat, Adiyaman.

\footnotetext{
${ }^{6}$ Kaynak kişileri burada toplu olarak sıralamayı tercih ettik. Vefat etmiş olan kaynak kişilerden aktarımı “ALKAYIŞ Saadet” yapmıştır.
} 